\title{
BMJ Open Testing for sexually transmitted infections among students: a discrete choice experiment of service preferences
}

\author{
Carrie D Llewellyn, ${ }^{1}$ Chloe Sakal, ${ }^{1}$ Mylene Lagarde, ${ }^{2}$ Alex Pollard, ${ }^{1}$ Alec H Miners ${ }^{2}$
}

To cite: Llewellyn CD, Sakal C, Lagarde M, et al. Testing for sexually transmitted infections among students: a discrete choice experiment of service preferences. BMJ Open 2013;3:e003240. doi:10.1136/bmjopen-2013003240

- Prepublication history for this paper is available online To view these files please visit the journal online (http://dx.doi.org/10.1136/ bmjopen-2013-003240).

Received 16 May 2013 Revised 6 September 2013 Accepted 24 September 2013

CrossMark

${ }^{1}$ Division of Public Health \& Primary Care, Brighton \& Sussex Medical School, Brighton, UK

${ }^{2}$ Faculty of Public Health and Policy, London School of Hygiene and Tropical Medicine, University of London, London, UK

Correspondence to Dr Carrie Llewellyn; c.d.llewellyn@bsms.ac.uk

\section{ABSTRACT}

Objectives: To assess preferences among students for sexually transmitted infection (STI) testing services, with a view to establishing strength of preference for different service attributes.

Design: Online discrete choice experiment (DCE) questionnaire.

Setting: South East of England.

Participants: A convenience sample of 233 students from two universities.

Outcomes: Adjusted ORs in relation to service characteristics.

Results: The study yielded 233 responses.

Respondents' ages ranged from 16 to 34 years with a mean age of 22 years. Among this sample, the respondents demonstrated strong preferences for a testing service which provided tests for all STIs including syphilis, herpes and HIV (OR 4.1; $95 \% \mathrm{Cl}$ 3.36 to 4.90 ) and centres staffed by a doctor or nurse with specialist knowledge of STIS (OR $2.1 ; 95 \% \mathrm{Cl}$ 1.78 to 2.37 ). Receiving all test results, whether positive or negative, was also significantly preferable to not being notified when tests were all negative ('no news is good news'; OR $1.3 ; 95 \% \mathrm{Cl} 1.16$ to 1.5 ). The length of time waiting for an appointment and the method by which results are received were not significant service characteristics in terms of preferences. Patient level characteristics such as age, sex and previous testing experience did not predict the likelihood of testing.

Conclusions: This study demonstrates that of the examined attributes, university students expressed the strongest preference for a comprehensive testing service. The next strongest preferences were for being tested by specialist STI staff and receiving negative as well as positive test results. However, it remains unclear how strong these preferences are in relation to characteristics which were not part of the study design and whether or not they are cost-effective.

\section{INTRODUCTION}

The incidence rate of diagnosed sexually transmitted infections (STIs) in the UK has increased significantly over the past 10 years, ${ }^{1}$ with young people between the ages

\section{ARTICLE SUMMARY}

Strengths and limitations of this study

- Its discrete choice design, an approach that requires people to make explicit trade-offs between service characteristics and allows the relative strength of different service characteristics to be assessed.

- This study is limited by its convenience sample and its ability to generalise to 'young people' other than university students.

- The relatively modest sample size meant that further analysis of preference heterogeneity could not be assessed.

of 16-24 years of age being at high risk of contracting an STI. ${ }^{1}$ Despite advances in screening programmes and treatment, the STI rates remain high, highlighting the importance of identifying the risk factors associated with the spread of infection in order to minimise costly treatment and further medical complications of becoming infected, such as pelvic inflammatory disease and infertility. ${ }^{2}$

The UK's National Strategy for Sexual Health and $\mathrm{HIV}^{3}$ and the more recent British Association of Sexual Health and HIV (BASHH) endorsed standards of care $^{4}$ emphasise that future STI-related services should be based on people's preferences and respond to the needs of different user groups. Only a few studies have assessed preferences for STI testing services (other than HIV) in the $\mathrm{UK}^{5-8}$ and research specifically into young people's preferences for STI testing services is lacking. In terms of methods for assessing patient preferences, only one study has used a choice-based approach, such as a discrete choice experiment (DCE) design. ${ }^{7}$ Such studies are useful as they allow a direct assessment of the relative preferences for different service configurations or treatment approaches. ${ }^{9}$ The results from a recent $\mathrm{DCE}^{7}$ suggested that 
the most important issues to people testing for STIs were the comprehensiveness of testing and whether centres are staffed by STI specialists. The results also suggested that STI service users would generally prefer to 'drop in and wait' for tests compared with alternative appointment systems and that there was a strong preference for receiving negative and positive test results rather than only positive results ("no news is good news'). However, one of the main limitations of the study was that it only included people who were currently attending STI testing services. Moreover, participants were only offered the option to choose between one of two service scenarios and were not given the option to decline a test if neither scenario was preferable. Thus, the objective of the current study was to apply a similar DCE method with an alternative participant group of individuals who were not currently testing for STIs (not recruited from a clinic setting) in order to also include individuals who had never previously tested. Given that young people have been identified as a highrisk group for contracting STIs, we were also interested in sampling from this population. The added value of conducting this study meant that it was possible to assess whether the health service attributes and demographic variables were predictive of choosing to test for an STI in the first instance, and therefore whether changes to current service configurations could encourage testing behaviour.

\section{METHODS}

\section{Design: a DCE}

A cross-sectional online self-completion questionnaire assessing a range of preferences with regard to STI testing using DCE methodology was used. ${ }^{9-11}$ DCEs require respondents to choose between a number of competing service options that vary in terms of their design and the outcomes they produce. Each service option is described in terms of a number of attributes (eg, the time it takes to receive test results) and levels (eg, the same day, 1 or 5 days) and is compared with at least one alternative. The participant is required to select their preferred set of choices from at least two competing sets. The overall results indicate the relative preference of each attribute and level. A DCE questionnaire was previously constructed for use with a clinical population of current service users (see Miners et $a l^{7}$ and Llewellyn et $a l^{12}$ for more detail on the development of the questionnaire and selection of attributes. Each choice set contained six attributes (3 with 4 levels and 3 with 2 levels): waiting time for an appointment; who conducts the test; waiting time to receive results; how results are received; whether both positive and negative results are given, which STIs are tested for (see table 3). Questions were prefaced with the statement: 'Please answer these questions as if you needed an STI test. Choose just one option by ticking one of the boxes'. The participants were presented with three sets of choices, 'Option A', 'Option B' or a 'Prefer not to test' option, (see table 1 for an example). The 'no testing option' was not investigated in the original study.

The questionnaire was developed with the SAS software ${ }^{13}$ ensuring that the design was D-efficient. The final design included 16 choice sets, which were blocked (halved) and a second version of each block produced so that the questions appeared in a different order (to minimise response bias). A single test of consistency (in which one option was logically superior to the other) was added to each block in order to gauge how difficult participants found the DCE task and/or how much attention they paid to the questions. This meant that each participant was required to answer nine DCE questions. Respondents were also asked to provide basic background information such as age, sex, sexual

Table 1 Choice set representing three options

\begin{tabular}{|c|c|c|c|}
\hline & Prefer option A & Prefer option B & $\begin{array}{l}\text { Prefer not } \\
\text { to test }\end{array}$ \\
\hline $\begin{array}{l}\text { How long do you have to wait for an } \\
\text { appointment after first contacting } \\
\text { the service? }\end{array}$ & $\begin{array}{l}\text { An appointment at your } \\
\text { convenience after } 48 \mathrm{~h}\end{array}$ & Drop in the same day and wait & \\
\hline Who conducts your tests? & $\begin{array}{l}\text { A doctor or nurse without } \\
\text { specialist STI knowledge }\end{array}$ & $\begin{array}{l}\text { A doctor or nurse with specialist STI } \\
\text { knowledge }\end{array}$ & \\
\hline $\begin{array}{l}\text { How long do you have to wait after } \\
\text { being tested before you get your } \\
\text { results? }\end{array}$ & Wait 3 days for results & Wait 7 days for results & \\
\hline How do you get your test results? & Get results by email & $\begin{array}{l}\text { Get results by post to your home } \\
\text { address }\end{array}$ & \\
\hline Which test results do you get? & $\begin{array}{l}\text { You are told test results only if } \\
\text { you have an infection (positive } \\
\text { results only) }\end{array}$ & $\begin{array}{l}\text { You are told all test results whether } \\
\text { you have an infection or not (positive } \\
\text { and negative results) }\end{array}$ & \\
\hline How many STIs are you tested for? & $\begin{array}{l}\text { Most STIs are tested for but not } \\
\text { syphilis, herpes and HIV }\end{array}$ & $\begin{array}{l}\text { All STIs are tested for including } \\
\text { syphilis, herpes and HIV }\end{array}$ & \\
\hline
\end{tabular}


orientation, previous STI testing (yes/no) and presence of STI symptoms (yes/no), all of which could feasibly influence preference of service.

\section{Participants and procedure}

To recruit participants from the student population, we created an online survey using Survey Monkey for 3 months (January 2011 to March 2011) and placed a link to it on the University of Brighton and University of Sussex student intranet homepages. The link forwarded volunteering participants to an HTML encoded button, which, when clicked, randomly assigned one of the four questionnaire versions to the participant. Participants did not have to have any prior knowledge of any STI testing services, including having previously used any STI services. Participants were given the opportunity to be entered into a prize draw to win a $£ 50$ Amazon voucher.

\section{Statistical analyses}

Multinomial logistic (MNL) regression techniques were used to analyse the results as participants could choose between three responses (option A, option B or 'prefer not to test'). As there was reason to believe that the probabilities of choosing option A and B were likely to be related, compared with a preference for not testing, the appropriateness of analysing the results using nested logistic (NL) regression techniques was first investigated. However, the results (not shown) did not support the use of an NL. The influence of patient level characteristics (age, sex and STI testing history (yes/no)) on the likelihood of not choosing to test was also examined. Robust SEs were reported for all models in order to account for multiple responses per participant. All of the statistical analyses were conducted in STATA V.12, ${ }^{14}$ using the asclogit commands.

The internal validity of the choice experiment was assessed by examining a number of statistics. First, by examining the face validity of the ORs on the attributes (eg, shorter waiting times should logically be preferred to longer times). Second, the percentage of respondents answering the consistency question illogically was reported, as was the percentage of questionnaires in which dominance occurred. That is, where respondents consistently based their choices on the same level on one attribute irrespective of the values on the remaining attributes.

\section{RESULTS}

Two hundred and thirty-three questionnaires were returned that reported baseline demographic data and at least one DCE response. Participant ages ranged between 16 and 34 years, with a mean of 22.4 years (table 2). The majority $(73 \%)$ reported having previously tested for an STI, although only $15 \%$ had received treatment following a diagnosis. Nearly $80 \%$ of respondents classified themselves as 'white British'.
Table 2 The demographic and self-reported characteristics of the study respondents $(n=233)$

\begin{tabular}{|c|c|c|}
\hline Characteristics & Frequency & Per cent \\
\hline Mean age in years (SD) & $22.2(2.8)$ & \\
\hline Range* $^{*}$ & $16-34$ years & \\
\hline \multicolumn{3}{|l|}{$\mathrm{Sex}^{*}$} \\
\hline Female & 140 & 64 \\
\hline \multicolumn{3}{|l|}{ Ethnicity* } \\
\hline White British & 173 & 79 \\
\hline Other & 46 & 21 \\
\hline \multicolumn{3}{|l|}{ Sexual preference* } \\
\hline Heterosexual & 193 & 88 \\
\hline Homosexual & 13 & 6 \\
\hline Bisexual & 11 & 5 \\
\hline Prefer not to say & 2 & 1 \\
\hline \multicolumn{3}{|c|}{ Believes currently has STI symptoms $\dagger$} \\
\hline Yes & 4 & 2 \\
\hline No & 216 & 98 \\
\hline \multicolumn{3}{|l|}{ Previous STI test?† } \\
\hline Yes & 161 & 73 \\
\hline No & 59 & 27 \\
\hline \multicolumn{3}{|c|}{ Previous treatment for STI?† } \\
\hline Yes & 33 & 15 \\
\hline No & 187 & 85 \\
\hline \multicolumn{3}{|c|}{ Previously tested at the GP surgery?† } \\
\hline Yes & 49 & 22 \\
\hline No & 171 & 78 \\
\hline \multicolumn{3}{|c|}{ Previously tested at the STI/GUM clinic?† } \\
\hline Yes & 87 & 40 \\
\hline No & 133 & 60 \\
\hline
\end{tabular}

Of the 233 respondents, $n=18(8 \%)$ failed to answer the consistency question logically, indicating that most people understood and/or paid attention to the DCE task. Less than $1 \%(38 / 5439)$ of the completed DCE responses indicated a preference for 'not testing', corresponding to 20 individuals. A total of $86 \%$ of the DCE questions were answered. The tests for dominance revealed that $25 \%$ of individuals always chose a service operating a 'drop in the same day and wait' appointment system. The percentage of dominant responses for the remaining attributes was negligible.

\section{DCE RESULTS}

The results from the MNL model showed that age, sex or whether individuals had previously tested for an STI were not associated with an increased likelihood of choosing to test $(p>0.20$ in all instances (table 3$))$. The reported ORs on the main DCE attributes were generally in the expected direction, providing a degree of support for the validity of the model. For example, respondents preferred shorter to longer waiting times for test results (table 3). The model predicted $84 \%$ of choices correctly. 
Table 3 Preferences for STI testing characteristics and demographic predictors of choosing to test derived using the (ASCL) model, expressed as ORs

\begin{tabular}{|c|c|c|c|}
\hline Attributes and levels & ORs & Cl & p Value \\
\hline \multicolumn{4}{|l|}{ Time to appointment } \\
\hline Drop in the same day and wait & 0.97 & 0.68 to 1.39 & 0.89 \\
\hline Within $24 \mathrm{~h}$ & 0.91 & 0.73 to 1.15 & 0.44 \\
\hline Within $48 \mathrm{~h}$ & 1.0 & - & - \\
\hline After $48 \mathrm{~h}$ but at the individual's convenience & 1.04 & 0.83 to 1.30 & 0.72 \\
\hline \multicolumn{4}{|l|}{ Results waiting time } \\
\hline Same day & 1.45 & 1.10 to 1.91 & 0.009 \\
\hline 3 days & 1.25 & 1.02 to 1.53 & 0.035 \\
\hline 7 days & 1.0 & - & - \\
\hline 21 days & 0.48 & 0.37 to 0.62 & $<0.001$ \\
\hline \multicolumn{4}{|l|}{ Comprehensive of results } \\
\hline Positive results only & 1.0 & - & - \\
\hline Positive and negative results & 1.32 & 1.16 to 1.50 & $<0.001$ \\
\hline \multicolumn{4}{|l|}{ Staff } \\
\hline Staff without specialist STI knowledge & 1.0 & - & - \\
\hline Staff with specialist STI knowledge & 2.05 & 1.78 to 2.37 & $<0.001$ \\
\hline \multicolumn{4}{|l|}{ Comprehensiveness of testing } \\
\hline Tests for most STIs* & 1.0 & - & - \\
\hline Tests for all STIs & 4.06 & 3.36 to 4.90 & $<0.001$ \\
\hline \multicolumn{4}{|l|}{ Results reporting method } \\
\hline Phone up test centre & 1.0 & - & - \\
\hline Post to home address & 0.64 & 0.52 to 0.79 & $<0.001$ \\
\hline By email & 1.07 & 0.84 to 1.35 & 0.60 \\
\hline Text or call to mobile phone by centre & 1.20 & 0.98 to 1.48 & 0.07 \\
\hline \multicolumn{4}{|l|}{ Patient level characteristics } \\
\hline \multicolumn{4}{|l|}{ Choose test option A } \\
\hline Age & 1.22 & 0.42 to 3.59 & 0.71 \\
\hline Sex & 0.91 & 0.79 to 1.06 & 0.22 \\
\hline Previous STI test & 1.32 & 0.41 to 4.25 & 0.64 \\
\hline \multicolumn{4}{|l|}{ Choose test option B } \\
\hline Age & 1.03 & 0.36 to 2.96 & 0.96 \\
\hline Sext & 0.93 & 0.80 to 1.07 & 0.30 \\
\hline Previous STI test & 1.35 & 0.43 to 4.22 & 0.60 \\
\hline Choose not to test & 1.0 & - & - \\
\hline \multicolumn{4}{|c|}{$\begin{array}{l}\text { *Excluded tests were syphilis, herpes and HIV. } \\
\text { tWhere male is the reference group. } \\
\text { †Where not previously tested for a STI is the reference group. } \\
\text { For the main unadjusted model: log-likelihood }-977, \text { number of observations } 5256, \text { number of groups (participants) } 219, \text { Wald } \chi^{2}=422 \\
\text { (p<0.001), McFadden's adjusted } r^{2}=0.12 \text {, the model predicts } 84 \% \text { of answers correctly, an OR of } 1 \text { indicates the base alternative. } \\
\text { ASCL, alternative specific conditional logistic; STI, sexually transmitted infection. }\end{array}$} \\
\hline
\end{tabular}

Of all the attributes and levels, respondents indicated the strongest preferences for comprehensive testing (OR 4.06 ; $95 \%$ CI 3.36 to 4.90 ) and for attending clinics staffed by specialists (OR 2.05; $95 \%$ CI 1.78 to 2.37 ). Participants also expressed a preference for receiving all test results rather than only positive results (OR 1.32; $95 \%$ CI 1.16 to 1.50 ) and for receiving test results sooner rather than later. For example, the OR for receiving test results the same day rather than a week later was 1.45 (95\% CI 1.10 to 1.91 ). Respondents preferred to phone up to receive test results rather than to receive them by post (OR $0.64 ; 95 \%$ CI 0.52 to 0.79 ). None of the 'time to appointment' parameters achieved statistical significance, suggesting that all the other attributes included in this study were more important to individuals when deciding where to test.

While choosing service option 'A' or 'B' has no immediate interpretation, since they are generic descriptions that have no underlying meaning, the patient level characteristics and associated ORs relating to a testing option, be it 'A' or B', provide an understanding of the importance of each characteristic in terms of the overall decision not to test (table 3). None, however, were found to be predictive. For example, neither the OR relating to 'sex' for option 'A' (OR 0.91; 95\% CI 0.79 to 1.06 ) or 'B' (OR $0.93 ; 95 \%$ CI 0.80 to 1.07 ) achieved statistical significance, suggesting that there is no reason to believe women were more likely to choose not to test than men. 


\section{DISCUSSION}

Statement of principal findings

This DCE demonstrates that students currently without an STI had strong preferences for testing services that provide tests for all infections rather than a limited range, and for services staffed by a doctor or nurse with specialist knowledge of STIs rather than staff without it. Receiving all test results, whether positive or negative, was also found to be significantly preferable to only being notified of positive results ("no news is good news'). Respondents also preferred to receive test results sooner rather than later, but the time to an appointment and the method of receiving test results were less important for this sample of university students. There was no evidence to suggest that personal characteristics (age, sex and testing history) were predictive of choosing to test.

\section{Relation to wider literature}

We recently reported the results of a study using the same DCE questionnaire in an STI 'testing' population across different testing services. ${ }^{7}$ While the ORs on the service attributes differ across the studies, their order of importance remains broadly similar, except that in this study none of the levels on the time to appointment attribute attained statistical significance.

Unlike the previous study, this analysis included an option not to test, in order to assess the importance of the service level and patient level characteristics on this decision. Less than $1 \%$ of responses indicated a preference not to test, suggesting that the service level characteristics were not predictive of this decision and that altering them is unlikely to affect overall testing levels. Patient level characteristics, age, sex and testing history were not predictive of testing uptake.

The results demonstrated that there were certain STI testing service attributes that were more desirable than others when compared with each other. Of these attributes, receiving a complete test for all STIs, including HIV, syphilis and herpes, was valued four times more highly than a service offering limited testing. This would suggest that, given a choice, STI testing services for the detection of one STI only (eg, The National Chlamydia Screening Programme (NCSP)) would prove less desirable to young people than a full screen, if all other testing characteristics are held equal. In a larger study involving a clinical sample of current testers, an age effect was found whereby preferences for comprehensiveness of testing increased with age. However, younger people under 25 years of age were still twice as likely to prefer a testing service offering tests for all STIs, including HIV, than a service offering a less comprehensive service. $^{7}$ The differences found in the strength of preference between the current study and the previous study could be attributed to the differences in the sample, the current respondents being all university students, or differences in the survey administration mode (online vs face to face).
The participants in this study indicated a preference for tests to be carried out by a staff member with perceived specialist STI knowledge. It could be speculated that specialists are perceived to hold a greater level of knowledge and therefore are able to provide better quality of care. Assumptions based on the healthcare professional regarding quality of care have been found to influence the desirability of the service. In a similar study of STI service preferences, Ross $e t a l$ failed to find any differences in preferences between general practitioners and genitourinary medicine specialists conducting the tests; however, more recent work has concluded that patients with past experience of STI testing have strong preferences for perceived 'STI specialist' staff. ${ }^{7}$ It is quite likely that this preference is influenced by existing relations with general practice and whether the patient has other medical conditions requiring specialist treatment such as HIV. ${ }^{12}$ Inconsistent with these findings is the preferences for home sampling. Previous studies have found that women prefer self-sampling for Chlamydia at home rather than attending a clinic, ${ }^{15} 16$ suggesting that although a doctor or nurse with specialist knowledge may be preferential to one without knowledge, the complete absence of a healthcare professional may ultimately be preferred by some people. This was not an aspect that was tested in the present study.

\section{Strengths and weaknesses}

The major strength of this preference study is its discrete choice design, an approach that requires people to make choices and allows the relative strength of different service characteristics to be assessed. This study is limited by its convenience sample and its inability to generalise to 'young people' other than university students. Compared with the student demographics from both universities, our sample consisted of slightly more females $(64 \%$ vs $55-61 \%)$ and was a few years younger on average (mean age 22 years vs 25-26 years). We were not able to assess what proportion of our sample was registered with which university. The questionnaire itself also presents limitations. Eighteen participants failed to answer the consistency question correctly, demonstrating a lack of understanding in completing the questionnaire. This is well within the acceptable limits of similar published studies, and there is no final consensus as to whether including or excluding those that failed the consistency question in analyses is the most appropriate method. Bias arising from a consistent order of questions within the questionnaire was eliminated by randomising different versions of the questionnaire containing questions in a different order.

The analysis showed that $25 \%$ of respondents always chose the option to test at a site operating a 'drop in the same day and wait' system, irrespective of other service characteristics. While the related attribute OR did not achieve statistical significance (it represents an average across all respondents), this finding suggests that there is significant unexplained heterogeneity in preferences 
within the sample, and that this service characteristic is particularly important to some, as yet indefinable, group.

The aim of the study was to indicate the strength of 'patient' preference for a number of STI-related service characteristics. However, there are a number of potentially competing perspectives in terms of appropriate policy recommendations given the results. For example, while respondents clearly indicated a preference to be tested for all infections, rather than some, it might not be clinically appropriate or cost-effective to do so in all instances. Perhaps on this particular issue, an appropriate policy decision could be not to literally offer tests for all infections, but rather to ensure that people are offered the opportunity to be tested for common infections given their particular demographic, in single, rather than multiple clinic visits.

A final limitation with this study, and DCEs in general, is that the results are relative to each other and should not be over-interpreted. For example, while out of the six attributes the strongest preference was shown for comprehensive testing services, individuals might have even stronger preferences for attributes that were not included in the study design. Therefore, while we believe that the results are robust in terms of how the ORs for the included attributes relate to each other, we are unclear how they might relate to other potential service characteristics such as 'clinic opening hours' or 'parking facilities'.

\section{Implications}

The NCSP was implemented to target young people for Chlamydia testing, the most commonly diagnosed STI in the UK. Although Chlamydia is the most common STI among this age group, it is feasible that any STI can be transmitted by unprotected sex, although we are not advocating that students be routinely screened for less prevalent infections such as syphilis and HIV. However, our results indicate that, given a choice, young people would prefer to be tested for all STIs, including HIV, rather than a limited selection. Given these preferences, it may be helpful to young people to explain why tests for other infections are not routinely given and under what circumstances it would be desirable to be screened for a wider selection of STIs.

The application of this study in the use of developing an STI testing service that appeals to young people could be furthered by gaining a larger and more diverse sample size of young people. Future studies may aim to explore the preferences of younger college-aged students, and those not in education, in order to obtain more participants between the ages of 16 and 18 years. Student data could be gained using alternative methods such as mobile phone applications.

Although barriers to STI testing among young people, such as shame, embarrassment, anxiety ${ }^{17-19}$ and lack of symptoms, ${ }^{20}{ }^{21}$ have been identified previously, there is a lack of evidence to support the role of the actual testing service as an influential factor for acquiring an STI test. Although this study demonstrates preferable aspects of STI testing service for this sample of young people, it does not necessarily follow that implementing such a service would influence the decision to test. It is unclear whether barriers hindering the initial decision to acquire an STI test, such as lack of symptoms or embarrassment, outweigh service improvements.

\section{CONCLUSIONS}

Results demonstrated a hierarchy of STI testing service attributes that are preferable to university students. By implementing an STI testing service that appeals to young people, it may be possible to increase testing rates, with a view to decreasing the incidence of STIs in this high-risk group. However, further research is needed to identify the impact of preferable STI testing services on STI testing uptake rates in order to establish whether implementing a preferable service would prove cost-effective in the management of STIs in young people.

Contributors AHM and CDL devised the study. ML generated the factorial design. AHM undertook the statistical analysis with advice from ML. CS and AP were responsible for data collection. CS, CDL and AHM wrote the first draft of the manuscript. All authors contributed to the write-up and approval of the final version.

Funding This research received no specific grant from any funding agency in the public, commercial or not-for-profit sectors.

Competing interests None.

Patient consent Obtained.

Ethics approval Brighton \& Sussex Medical School Research Governance and Ethics Committee approval was granted (10/114/SAK).

Provenance and peer review Not commissioned; externally peer reviewed.

Data sharing statement No additional data are available.

Open Access This is an Open Access article distributed in accordance with the Creative Commons Attribution Non Commercial (CC BY-NC 3.0) license, which permits others to distribute, remix, adapt, build upon this work noncommercially, and license their derivative works on different terms, provided the original work is properly cited and the use is non-commercial. See: http:// creativecommons.org/licenses/by-nc/3.0/

\section{REFERENCES}

1. Public Health England. Health Protection Report: sexually transmitted infections and Chlamydia screening in England, 2012, 7 (23). Public Health England, 7 June 2013.

2. Hillis S, Owens L, Marchbanks P, et al. Recurrent Chlamydial infections increase the risks of hospitalisation for ectopic pregnancy and pelvic inflammatory disease. Am J Obstet Gynecol 1997;176:103-7.

3. Department of Health. Better prevention, better services, better sexual health-the National Strategy for Sexual Health and HIV. London: DOH, 2001.

4. Medical Foundation for AIDS \& Sexual Health. Standards for the management of sexually transmitted infections. 2010.

5. Brown L, Copas A, Stephenson J, et al. Preferred options for receiving sexual health screening results: a population and patient survey. Int J STD AIDS 2008;19:184-7.

6. Hambly S, Luzzi G. Sexual health services-a patient preference survey. Int J STD AIDS 2006;17:372-4.

7. Miners $\mathrm{AH}$, Llewellyn CD, Pollard A, et al. Assessing use preferences for sexually transmitted infection testing services: a discrete choice experiment. Sex Transm Infect 2012;88:510-16. 
8. Ross J, Copas A, Stephenson J, et al. Public involvement in modernising genitourinary medicine clinics: using general public and patient opinion to influence models of service delivery. Sex Transm Infect 2006;82:484-8.

9. Ryan M, Watson V, Gerard K. Practical issues in conducting a discrete choice experiment. In: Ryan M, Gerard K, Amaya-Amaya M. eds. Using discrete choice experiments to value health and health care. Dordrecht: Springer, 2008:73-88.

10. de Bekker-Grob E, Ryan M, Gerard K. Discrete choice experiments in health economics: a review of the literature. Health Econ 2012;21:145-72.

11. Ryan M. Discrete choice experiments in health care. $B M J$ 2004;328:360-1.

12. Llewellyn $C D$, Pollard $A$, Miners $A H$, et al. Understanding patient choices for attending sexually transmitted infection testing services: a qualitative study. Sex Transm Infect 2012;88:504-9.

13. Kuhfeld W. Market research methods in SAS. Cary, NC, USA: SAS Institute Inc, 2010.

14. StataCorp. Stata Statistical Software Release 12. College Station, TX, USA: StataCorp LP, 2011.
15. Graseck A, Secura G, Allsworth J, et al. Home compared with clinic-based screening for sexually transmitted infections: a randomized controlled trial. Obstet Gynecol 2010;116:1311-18.

16. Graseck A, Secura G, Allsworth J, et al. Home screening compared with clinic-based screening for sexually transmitted infections. Obstet Gynecol 2010;115:745-52.

17. Balfe M, Brugha R, O'Donovan D, et al. Triggers of self-conscious emotions in the sexually transmitted infection testing process. BMC Res Notes 2010;3:229.

18. Cunningham S, Tschann J, Gurvey J, et al. Attitudes about sexual disclosure and perceptions of stigma and shame. Sex Transm Infect 2002;78:334-8.

19. Uuskula A, Kangur K, McNutt L. Barriers to effective STI screening in a post-soviet society: results from a qualitative study. Sex Transm Infect 2006;82:323-6.

20. Balfe $M$, Brugha R. What prompts young adults in Ireland to attend health services for STI testing? BMC Public Health 2009;9:311.

21. Tilson E, Sanchez V, Ford C, et al. Barriers to asymptomatic screening and other STD services for adolescents and young adults: focus group discussions. BMC Public Health 2004;4:21. 